Letter to the Editor

\title{
Cardiovascular effects and safety of mannitol in treating raised intraocular pressure
}

\author{
Alp Atik BMed(Dist) MPH, ${ }^{1,2}$ Elsie Chan FRANZCO, ${ }^{1,2}$ Carmel Crock FACEM ${ }^{1}$ and Ghee \\ Soon Ang FRANZCO 1
}

\begin{abstract}
${ }^{1}$ Royal Victorian Eye and Ear Hospital, ${ }^{2}$ Centre for Eye Research Australia, University of Melbourne, Melbourne, Australia, 32 Gisborne Street East Melbourne VIC 3002
\end{abstract}

Correspondence: Brian Ang, 32 Gisborne Street East Melbourne VIC 3002

Brian.Ang@eyeandear.org.au

Received 24 November 2019; accepted 30 November 2019

Funding sources / Financial disclosure: None

Conflict of interest: None

This is the author manuscript accepted for publication and has undergone full peer review but has not been through the copyediting, typesetting, pagination and proofreading process, which may lead to differences between this version and the Version of Record. Please cite this article as doi: 10.1111/ceo.13695

This article is protected by copyright. All rights reserved. 
Mannitol is the most commonly used osmotic diuretic in ophthalmic emergency departments. Its primary use is in reducing intraocular pressure (IOP) $(1,2)$. The precise mechanism by which mannitol decreases IOP is not well understood, and may differ from its systemic vascular effect in inducing an osmotic pressure gradient. Mannitol administration protocols such as dosing and monitoring vary significantly $(3,4)$. There have also been several issues regarding side-effects including cardiovascular instability, metabolic acidosis, electrolyte imbalance and acute renal failure.

We conducted a retrospective chart review of patients presenting to an ophthalmology emergency department for acute, raised IOP to assess the use and adverse effects associated with mannitol infusion. A total of 132 patients were identified based on pharmacy dispensary coding at the Royal Victorian Eye and Ear Hospital (RVEEH). In all cases, mannitol was administered according to the RVEEH protocol: mannitol $20 \%(100 \mathrm{~g} / 500 \mathrm{~mL})$ was injected intravenously (IV) over at least 60 minutes at a dose of 1 to $2 \mathrm{~g} / \mathrm{kg}$ body weight ( 5 to $10 \mathrm{~mL} / \mathrm{kg}$ of $20 \%$ solution, up to a maximum of $100 \mathrm{~g}(500 \mathrm{~mL})$ ). Frail, elderly (>65 years) patients and people with pre-existing renal disease, taking nephrotoxic medications, pre-existing heart failure or pre-existing peripheral oedema were given a dose reduction of 0.5 to $1 \mathrm{~g} / \mathrm{kg}$ body weight ( 2.5 to $5 \mathrm{~mL} / \mathrm{kg}$ of $20 \%$ solution) up to a maximum of $50 \mathrm{~g}(250 \mathrm{~mL})$.

Contraindications to treatment included anuria due to severe renal disease, severe pulmonary congestion, frank pulmonary oedema, active intracranial bleeding, severe dehydration, hypersensitivity to mannitol, pre-existing plasma hyperosmolarity and severe heart failure.

Patients had the following parameters recorded before, during and after IV mannitol infusion: blood pressure (BP), pulse rate, temperature, respiratory rate, oxygen saturation. These were performed within 30 minutes prior to mannitol infusion, 15 to 45 minutes after commencement and between 30 to 120 minutes after cessation of 
the infusion. Systemic hypertension was defined as a systolic BP greater than $140 \mathrm{mmHg}$.

The mean age of patients was 58 (range 18 to 90) years, mean presenting IOP was $56 \mathrm{mmHg}$ and mean IOP following mannitol treatment was $27 \mathrm{mmHg}$. Mannitol caused an increase in systolic, diastolic and mean arterial pressure (MAP) during infusion which returned to baseline after cessation. The mean increase in systolic BP during mannitol infusion was $14.52 \mathrm{mmHg}(p<0.01,95 \% \mathrm{Cl} 12.35-16.69 \mathrm{mmHg})$ (Figure 1).

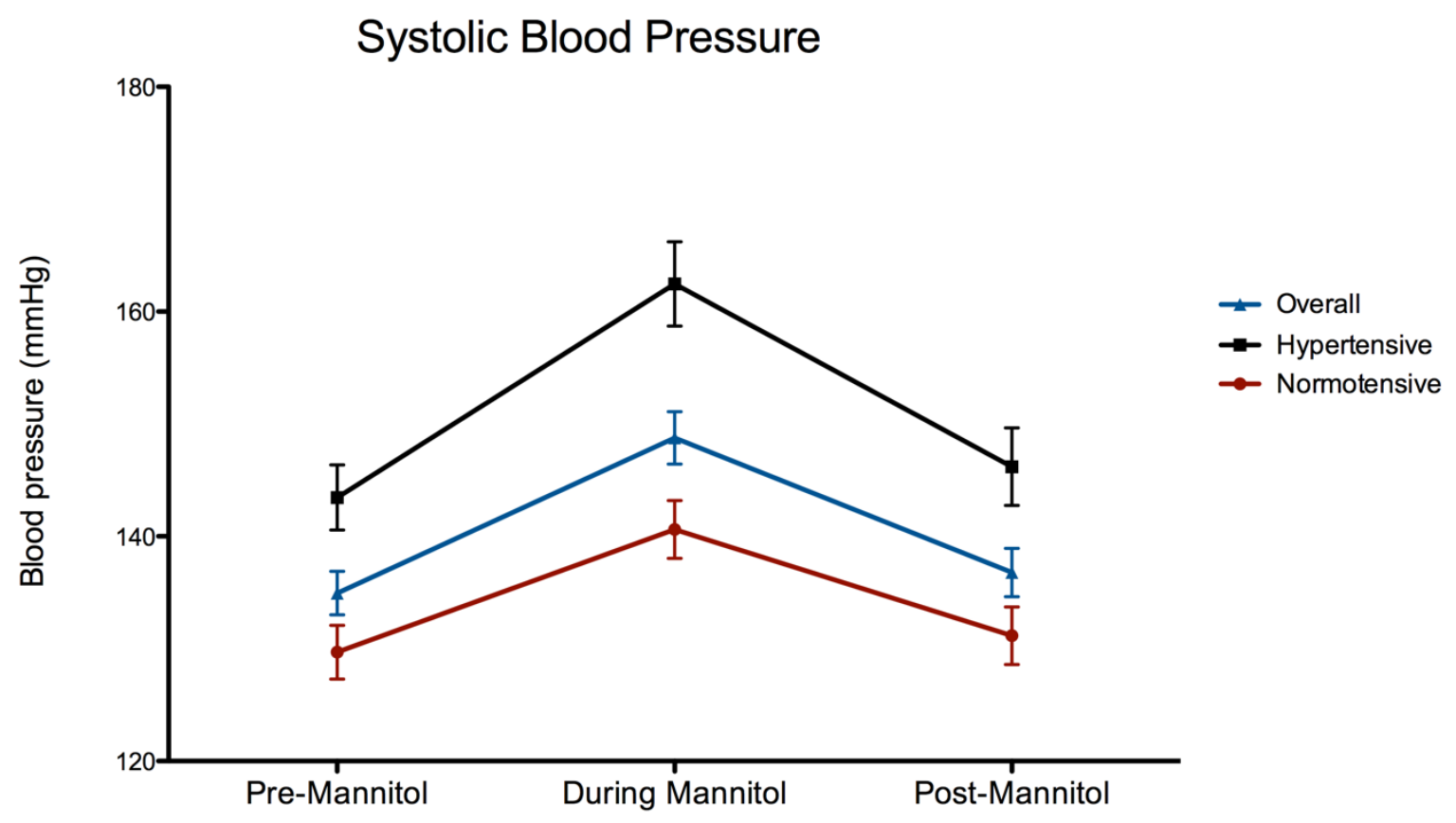

Figure 1: Mannitol increased systolic blood pressure by $14.52 \mathrm{mmHg}(p<0.01,95 \%$ Cl $12.35-16.69 \mathrm{mmHg}$ ). Patients with a history of hypertension had a systolic blood pressure increase of $20.21 \mathrm{mmHg}(p<0.01,95 \% \mathrm{Cl} 16.13-24.30 \mathrm{mmHg})$, compared to $11.14 \mathrm{mmHg}(p<0.01,95 \% \mathrm{Cl} 8.99-13.29 \mathrm{mmHg})$ in normotensive patients.

The mean increase in MAP was $6.49 \mathrm{mmHg}(p<0.01,95 \% \mathrm{Cl} 5.07-7.91 \mathrm{mmHg})$ (Figure 2). 


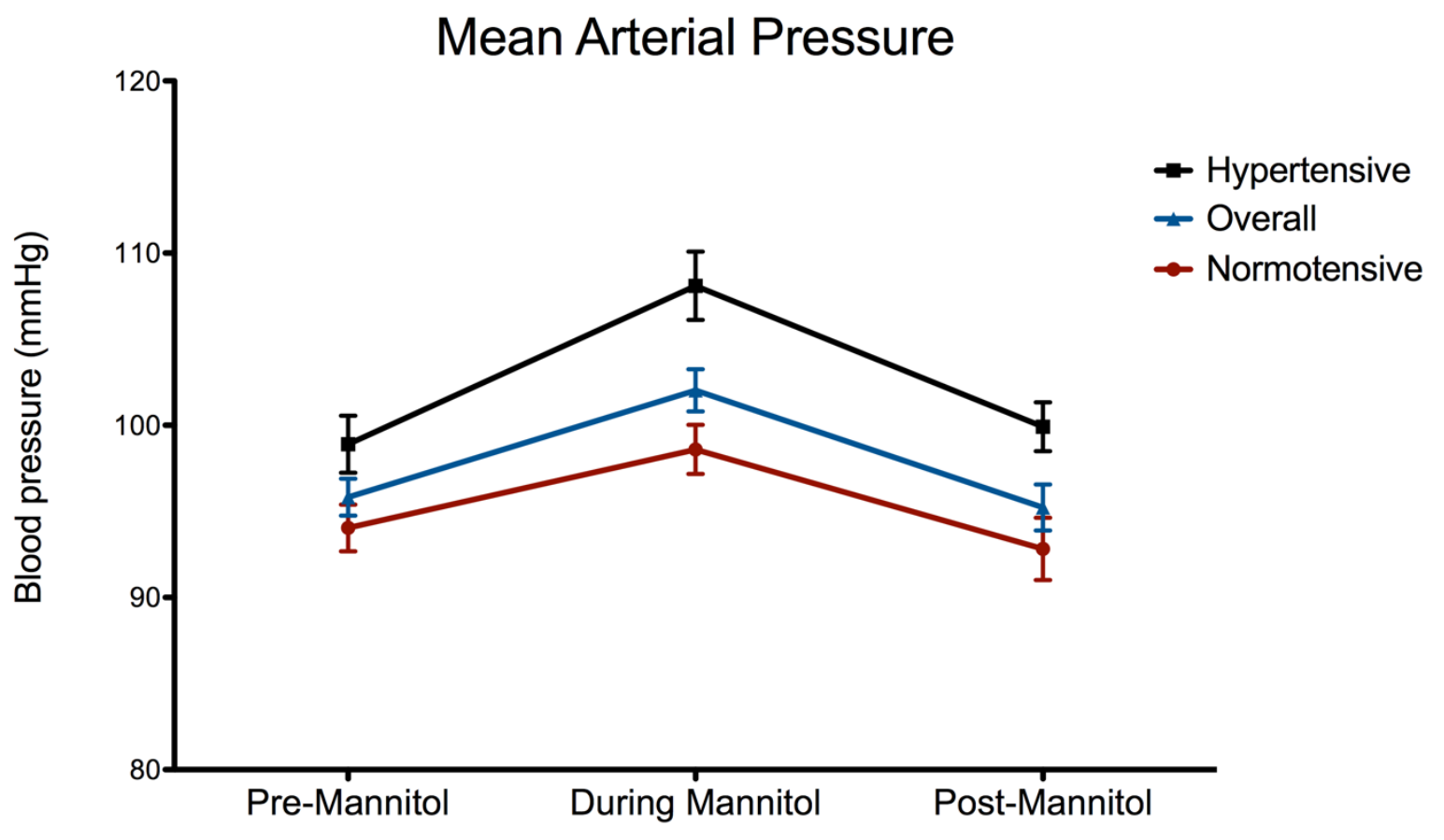

Figure 2: The mean increase in mean arterial pressure during mannitol infusion was $6.49 \mathrm{mmHg}(p<0.01,95 \% \mathrm{Cl} 5.07-7.91 \mathrm{mmHg})$. Patients with a history of hypertension had a mean arterial pressure increase of $9.19 \mathrm{mmHg}(p<0.01,95 \% \mathrm{Cl}$ $6.74-11.64 \mathrm{mmHg})$ compared to $4.89 \mathrm{mmHg}(p<0.05,95 \% \mathrm{Cl} 3.21-6.56 \mathrm{mmHg})$ in normotensive patients.

Patients with a history of hypertension had a mean systolic BP increase of $20.21 \mathrm{mmHg}(p<0.01,95 \% \mathrm{Cl} 16.13-24.30 \mathrm{mmHg}$ ), compared with $11.14 \mathrm{mmHg}$ $(p<0.01,95 \% \mathrm{Cl} 8.99-13.29 \mathrm{mmHg})$ in those without hypertension. Patients previously diagnosed with systemic hypertension were also more likely to have a greater increase in BP relative to normotensives with 33.3\% of hypertensive patients having a systolic BP increase over $20 \mathrm{mmHg}$ compared to $19.8 \%$ of normotensive patients (Table 1$)\left(\chi^{2}=12.451, p<0.05\right)$. 


\begin{tabular}{|c|c|c|c|}
\hline & $\begin{array}{c}\text { Overall } \\
n=132(\%)\end{array}$ & $\begin{array}{c}\text { Hypertensive } \\
n=48(\%)\end{array}$ & $\begin{array}{c}\text { Normotensive } \\
n=81(\%)\end{array}$ \\
\hline Increased BP & $117(88.6)$ & $46(95.8)$ & $69(85.2)$ \\
\hline$<10 \mathrm{mmHg}$ & $30(22.7)$ & $5(10.4)$ & $24(29.6)$ \\
\hline $10-20 \mathrm{mmHg}$ & $56(42.4)$ & $25(52.1)$ & $29(35.8)$ \\
\hline$>20 \mathrm{mmHg}$ & $31(23.5)$ & $16(33.3)$ & $16(19.8)$ \\
\hline No Change & $2(1.5)$ & $0(0)$ & $2(2.5)$ \\
\hline Decreased BP & $13(9.8)$ & $2(4.2)$ & $10(12.3)$ \\
\hline
\end{tabular}

Table 1: Proportion of patients with systolic blood pressure change during mannitol infusion. $X^{2}=12.451 p<0.05$

Age $(p<0.05)$, past medical history of systemic hypertension $(p<0.01)$, hypercholesterolaemia $(p<0.05)$, cardiovascular disease $(p<0.01)$ and use of blood pressure medications $(p<0.01)$ were all predictors for increased systolic BP during mannitol infusion on linear regression analysis.

There was a significant increase in pulse rate during mannitol infusion (Figure 3). The mean increase in pulse rate was 4.68 beats per minute $(\mathrm{bpm})(\mathrm{p}<0.01,95 \% \mathrm{Cl}$ 3.39-5.97bpm). Systemic BP did not predict a significant change in pulse rate. 


\section{Pulse Rate}

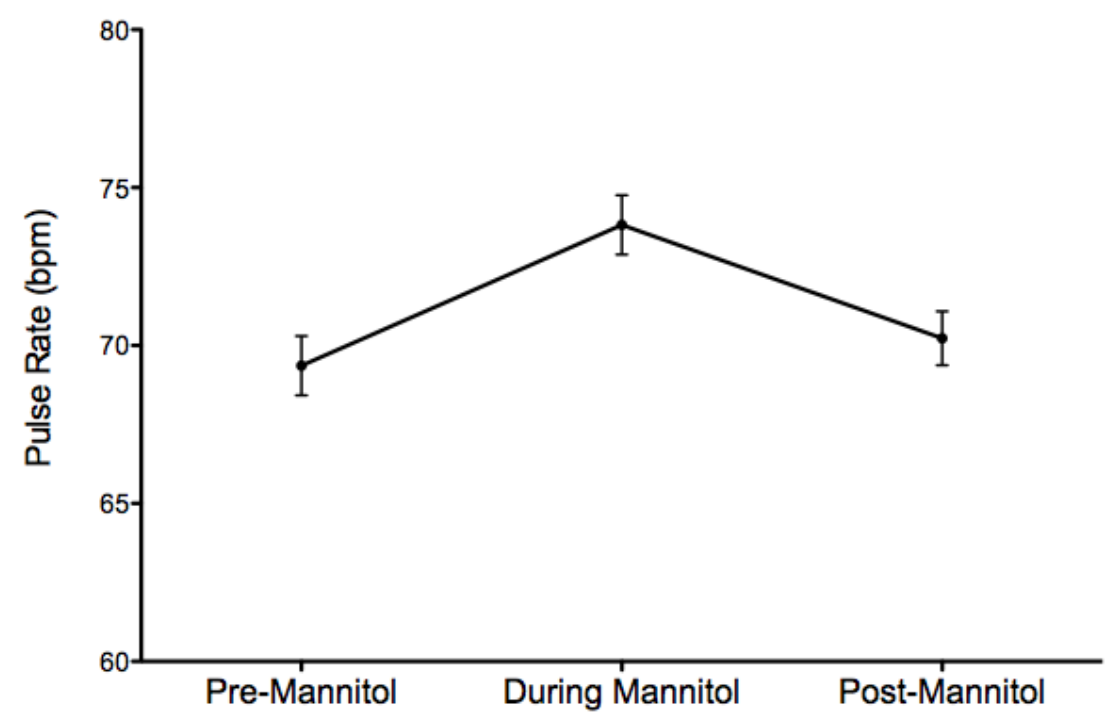

Figure 3: The mean increase in pulse rate during mannitol infusion was $4.68 \mathrm{bpm}$ $(p<0.01,95 \%$ Cl 3.39-5.98mmHg).

None of the patients in our study had a medical emergency associated with mannitol infusion and $86 \%$ did not record any side-effects. The most common side-effects included nausea and/or vomiting ( $9 \%)$, headache (4\%), dry mouth or thirst (1\%) and electrolyte imbalance (1\%).

Though our results may have recording bias due to incomplete notes or imprecise data entry with timing of observations, the data reflects real-world practice in a busy ophthalmic emergency department. The results from this audit suggests that with appropriate administration and monitoring, mannitol is a safe option in the management of acute, raised intraocular pressure. Patients with a history of cardiovascular disease (e.g. hypertension) should be monitored closely, as they are likely to experience an acute increase in blood pressure and pulse rate, which return to baseline at the conclusion of infusion. 


\section{REFERENCES}

1. Smith EW, Drance SM. Reduction of human intraocular pressure with intravenous mannitol. Arch Ophthalmol Chic III 1960. 1962 Dec;68: 734-7.

2. Weiss DI, Shaffer RN, Harrington DO. Treatment of malignant glaucoma with intravenous mannitol infusion. Medical reformation of the anterior chamber by means of an osmotic agent: a preliminary report. Arch Ophthalmol Chic III 1960. 1963 Feb;69:154-8.

3. Shawkat $\mathrm{H}$, Westwood M-M, Mortimer A. Mannitol: a review of its clinical uses. Contin Educ Anaesth Crit Care Pain. 2012 J an 12;12(2):82-5.

4. Takkar B, Chandra P, Shah R, Bhatia I, Roy S, Sihota R. Effect of Intravenous Mannitol on Intraocular Pressure in Vitrectomized Silicone-Oil-Filled Eyes. Semin Ophthalmol. 2017;32(6):672-5. 


\section{University Library}

\section{- M M N E R VA A gateway to Melbourne's research publications}

Minerva Access is the Institutional Repository of The University of Melbourne

Author/s:

Atik, A;Chan, E;Crock, C;Ang, GS

Title:

Cardiovascular effects and safety of mannitol in treating raised intraocular pressure

Date:

2020-04-01

Citation:

Atik, A., Chan, E., Crock, C. \& Ang, G. S. (2020). Cardiovascular effects and safety of mannitol in treating raised intraocular pressure. CLINICAL AND EXPERIMENTAL OPHTHALMOLOGY, 48 (3), pp.409-411. https://doi.org/10.1111/ceo.13695.

Persistent Link:

http://hdl.handle.net/11343/275588 